\title{
FAB MASS Spectrometry of 6-aminofulvene-2-aldimines: non classical aromatic compounds?
}

\author{
Christine Enjalbal, ${ }^{\dagger}$ Jean-Louis Aubagnac, ${ }^{*}{ }^{\dagger}$ Marta Pérez Torralba, ${ }^{\ddagger}$ Dionisia Sanz, ${ }^{\ddagger}$ Rosa \\ M. Claramunt, ${ }^{\ddagger}$ and José Elguero ${ }^{\S}$
}

UMR5810, Laboratoire des Aminoacides, Peptides et Protéines, Université de Montpellier II, F34095 Montpellier Cedex 5, France Departamento de Química Orgánica y Biología, Facultad de Ciencias, UNED, Senda del Rey 9, E-28040 Madrid, Spain and Instituto de Química

Médica, CSIC, Juan de la Cierva 3, E-28006 Madrid, Spain

E-mail: aubagnac@univ-montp2.fr

(received 12 Apr 00; accepted 26 Nov 00; published on the web 04 Dec 00)

\begin{abstract}
The use of meta-nitrobenzyl alcohol (NBA) as matrix allows to obtain better spectra than those recorded with the more popular matrix glycerol $(\mathrm{G})$ in the analysis of fulvene derivatives by FAB mass spectrometry. The influence of NBA on the mass spectra corresponds to its oxidative properties. Finally, the necessary structural information was easily obtained through tandem mass spectrometry experiments.
\end{abstract}

Keywords: FAB mass spectrometry, tandem mass spectrometry, aminofulvene-2-aldimines

\section{Introduction}

The characterisation of nitrogen containing compounds by FAB mass spectrometry ${ }^{1}$ is generally straightforward due to their basic properties. ${ }^{2}$ Compared to other less polar organic molecules such as ketones, alcohols or hydrocarbons, protonation of the nitrogen atom facilitates the ionization providing an abundant protonated molecular ion in the positive ion spectra. This behaviour considered as an advantage from an analytical point of view was nevertheless not observed for some families of nitrogen containing structures, ${ }^{3}$ like pyrazolo[1,2-a]pyrazoles 1 (Scheme 1). These compounds are certainly polar due to their zwitterionic character but their protonation is disfavoured since it would result in the loss of the aromaticity (Scheme 1). 
The peculiar behaviour in FAB mass spectrometry of nitrogen containing fulvenes 2 depicted in Scheme 2 and Table 1 is reported in this article.

* Correspondence to: J-L. Aubagnac; E-mail: aubagnac@univ-montp2.fr

$†$ Université de Montpellier II

† UNED

$\S$ IQM-CSIC
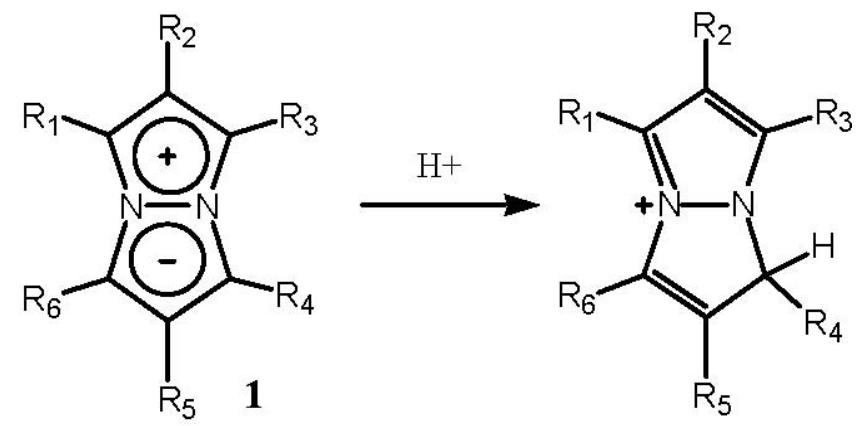

\section{Scheme 1}<smiles>[R3]N=CC1=CC=CC1=CN([R])[R]</smiles><smiles>O=CC1=CC=CC1=CO</smiles><smiles>[R]N1C=C2C=CC=C2C=[N+]([R3])C1</smiles>

\section{Scheme 2}

Table 1. 6-Aminofulvene-2-aldimines 2. Compound $\mathrm{R}_{1} \mathrm{R}_{2} \mathrm{R}_{3}$ Molecular Weight

2a $\mathrm{CH}_{3} \mathrm{CH}_{3} \mathrm{Pyr}^{a} 213$

2b $\mathrm{CH}_{3} \mathrm{CH}_{3} \mathrm{Tri}^{b} 215$

2c $\mathrm{C}_{6} \mathrm{H}_{5} \mathrm{H}^{c} \mathrm{C}_{6} \mathrm{H}_{5} 272$

2d $\mathrm{C}_{6} \mathrm{H}_{5} \mathrm{H}^{c} \mathrm{Tri}^{b} 263$

2e $\mathrm{C}_{6} \mathrm{H}_{5} \mathrm{H}^{c} \operatorname{Pyr}^{a} 261$

2f $\operatorname{Pyr}^{a} \mathrm{H}^{c} \operatorname{Pyr}^{a} 250$

${ }^{a} \mathrm{Pyr}=$-Pyrrolyl; ${ }^{b}$ Tri $=1 H-1,2,4$-triazolyl; ${ }^{c}$ These compounds are of type $\mathbf{4}$ (Scheme 2). 


\section{Experimental Section}

\section{Synthesis}

The syntheses of the studied compounds are described elsewhere. ${ }^{4}$

\section{Mass spectrometry}

FAB mass spectra were recorded on a Jeol JMS DX300 (Jeol Ltd, Tokyo, Japan). This instrument is of EB design. The energy of the neutral atom beam was $3 \mathrm{keV}$ (emission current 20 $\mathrm{mA}$ ). Calibration was accomplished using Ultramark 1621 (Heraus, Karlsruhe, Germany) as a reference. FAB mass spectra were measured at a mass resolution of 1000 . Xenon was used as the collision gas, at a pressure to reduce the beam of the parent ion by $30 \%$. The collision cell was located in the field-free region before the electric sector. The collision energy was $3 \mathrm{keV}$. The resulting fragment ions were analysed by the B/E linked scan method. Data were acquired and processed with a HP Apollo series data system (Palo Alto, CA, USA) using the Jeol complement software. Glycerol and meta-nitrobenzyl alcohol were purchased from Aldrich. The solutions were prepared by directly dissolving the compounds in methanol and a drop of the matrix on the probe tip.

\section{Results and Discussion}

There has been a considerable interest in non-classical aromatic compounds, and among them, 6hydroxyfulvene-2-aldehyde $3^{5,6}$ and 6-aminofulvene-2-aldimines $4^{7,8}$ have been extensively studied (Scheme 2). Compound $\mathbf{3}$ is one representative of what Gilli has called RAHB (Resonance Assisted Hydrogen Bond) characterised by an almost total delocalization of the $\pi$ system and very short $\mathrm{O} \cdots \mathrm{O}$ distances. ${ }^{6}$ Compounds of type 4 were described by MüllerWesterdorff who even considered the possibility that these systems belonged to the family of non-classical aromatic compounds. ${ }^{7}$ This model suggests that in the case of $\mathbf{3}$ and $\mathbf{4}$ the NH proton is in the middle of the hydrogen bond. Such assumption has been rejected, ${ }^{8}$ but, nevertheless, it remains that these structures do not possess lone pairs on the nitrogen which can be easily protonated.

Ionization pathways not requiring protonated structures, as commonly found in $\mathrm{FAB}$ mass spectrometry, were thus envisaged for these compounds. Therefore, three different processes of ionization have been evidenced and classified according to their ease of occurrence. ${ }^{9}$

First, direct desorptions of preformed ions generate abundant ions in the gaseous phase.

Second, acid-base reactions are commonly encountered, especially when dealing with 
biomolecules, producing protonated or deprotonated molecular ions.

Finally, redox reactions may also occur depending on the nature of the matrix used and the structures of the compounds under study. The loss of an electron is mainly observed when the oxidative NBA matrix is employed leading to the simultaneous formation of the molecular ion $\mathrm{M}^{+}$and $\mathrm{NBA}^{-3}$. In contrast to glycerol, NBA allowed to inhibit reduction phenomenon during FAB experiments. ${ }^{10,11}$

Since the studied compounds 2 (Table 1) are weakly basic, the following behaviours were expected in FAB mass spectrometry: (a) a less efficient ionization compared to what is usually observed for nitrogen containing molecules implying that matrix ions should appear with more important relative abundances. (b) the most significant positive ion spectra should be obtained with the NBA matrix. (c) competitive formation of $\mathrm{M}^{+}$and of $(\mathrm{M}+\mathrm{H})^{+}$should occur in the positive mode.

The recorded spectra displayed in Figures 1 to 4 confirmed the predicted behaviours. Similar results were reported by Takayama et al. for compounds of low polarity. ${ }^{12-14}$

Firstly, non-informative spectra were generated with glycerol since a unique structure (2b) showed a very weak protonated molecular ion. The relevance of the NBA matrix previously demonstrated with pyrazolo[1,2-a]pyrazoles ${ }^{3}$ was further confirmed by this work.

In the positive ion spectra of all studied compounds $2, \mathrm{M}^{+}$and $\mathrm{MH}^{+}$ions were detected with noticeable abundances as detailed in Table 2. Due to the presence in compounds $\mathbf{2} \mathbf{b}$ and $\mathbf{2} \mathbf{d}$ of the basic 4-H-1,2,4-triazol-4-yl moiety which can be easily protonated (for instance, 4-methyl-1,2,4triazole, $\left.\mathrm{p} K_{\mathrm{a}}=3.40\right),{ }^{15}$ the $\mathrm{MH}^{+} / \mathrm{M}^{+}$ratio is higher than for the other compounds. Figures 1 and 3 , which correspond to the spectra of compounds 2c and 2d, respectively, illustrate these differences. It should also be noted however that that the ratio is 3.12 for $\mathbf{2 d}$ but only 1.59 for $\mathbf{2 b}$. Thus, the $\mathrm{M}^{+}$ion must be more stabilised for the latter structure.

By comparing the FAB mass spectra of the six fulvenes 2 recorded with NBA as matrix, compound 2a was found to exhibit the most abundant molecular ion at $\mathrm{m} / \mathrm{z} 213$, matrix and fragment ions being weakly detected in this sample. The $\mathrm{M}^{+}$ion must be strongly stabilised as already discussed for compound $\mathbf{2 b}$ (see above). Therefore, despite the lack of RAHB, these two compounds $\left(\mathrm{R}_{1}=\mathrm{R}_{2}=\mathrm{CH}_{3}\right)$ are not easily protonated but they loss instead an electron yielding to a highly delocalised radical cation. 


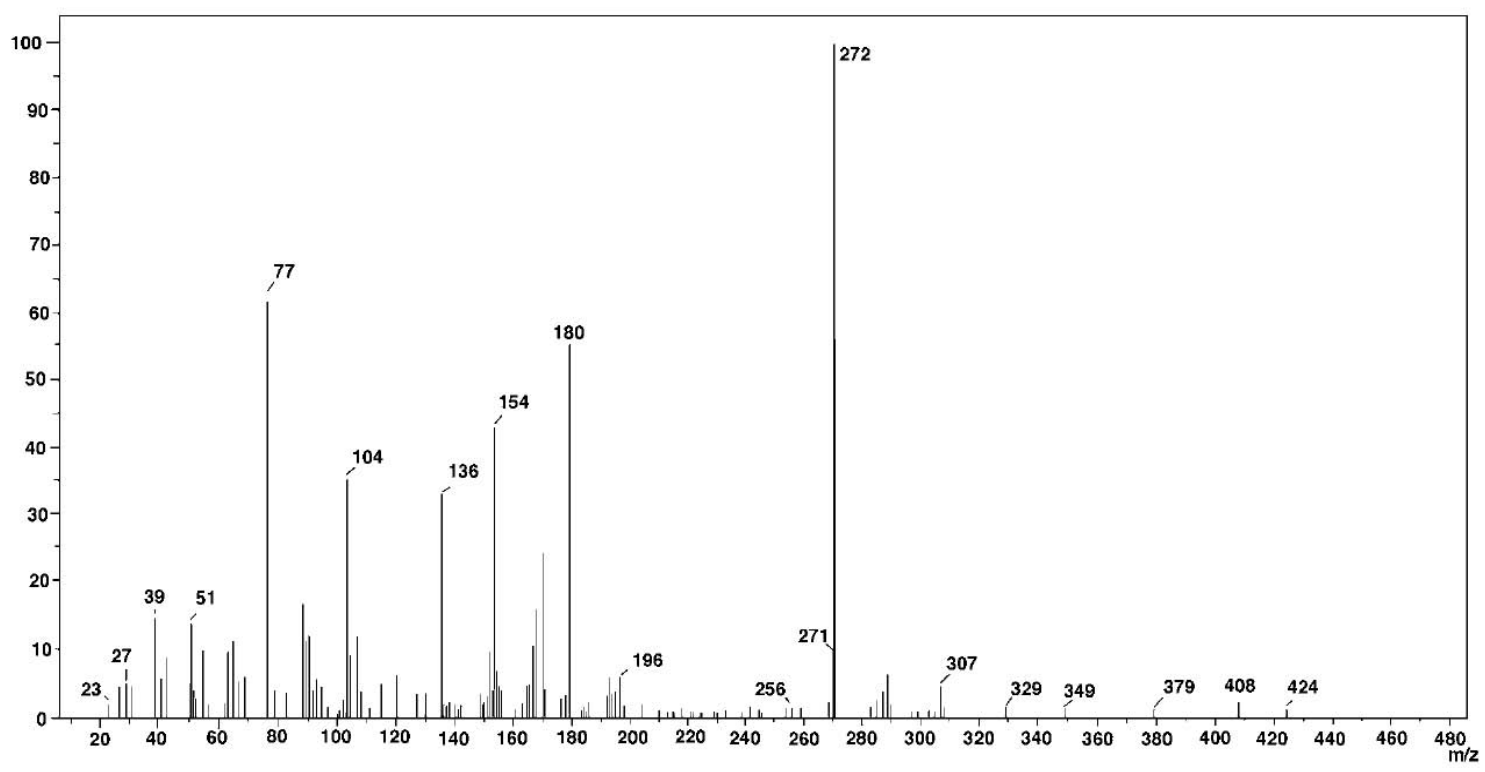

Figure 1. Positive ion FAB mass spectrum of compound $2 \mathrm{c}$ recorded with NBA

Considering the dipolar resonance forms of compounds 2 and 4, which are stabilised by the aromaticity of the cyclopentadienide anion, the electron which has been lost must come from the lone pair of the nitrogen atom bearing the $\mathrm{R}_{3}$ substituent. Consequently, the intramolecular hydrogen bond (IMHB) present in 4 should make difficult the loss of an electron and the concomitant formation of the $\mathrm{M}^{+}$species.

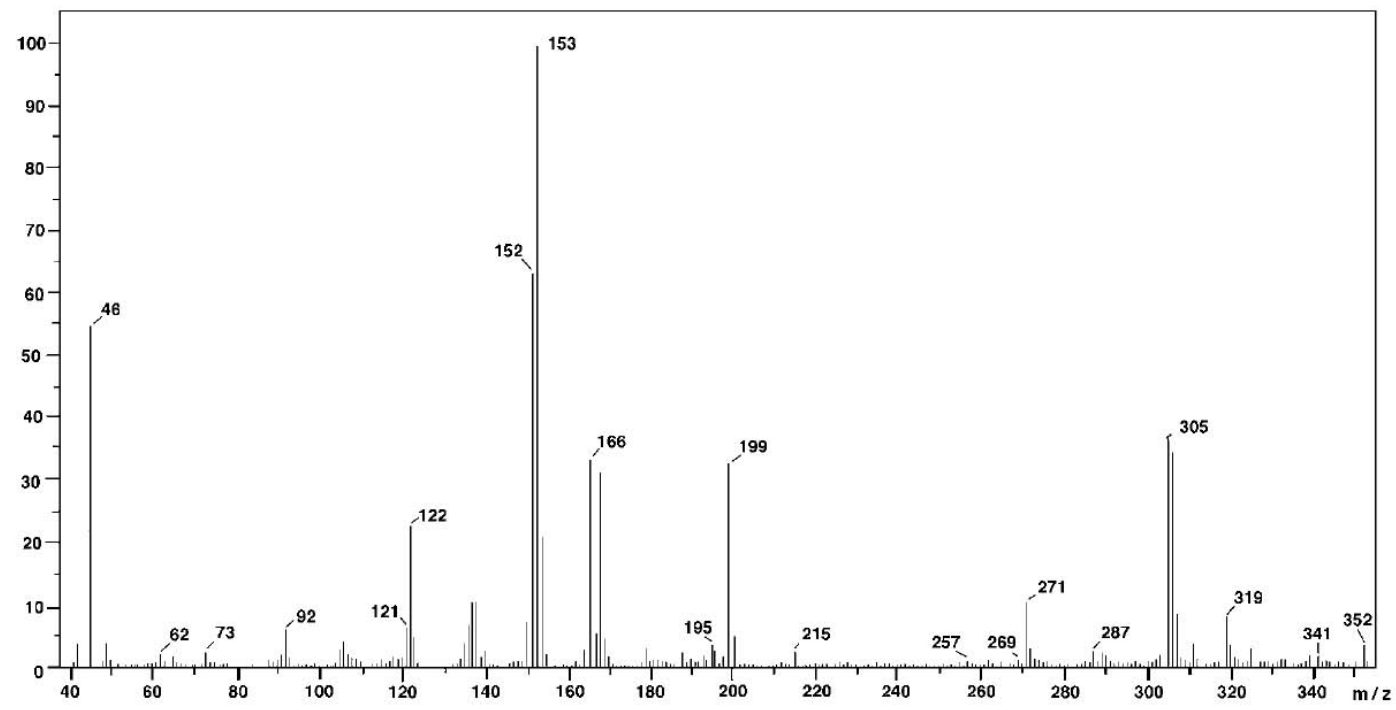

Figure 2. Negative ion FAB mass spectrum of compound $2 \mathrm{c}$ recorded with NBA 
Table 2. Positive ion Fast Atom Bombardment mass spectra (Matrix: NBA) ${ }^{\mathrm{a}}$

\begin{tabular}{|c|c|c|c|c|c|c|}
\hline Comp. & $\begin{array}{l}\text { Molecular } \\
\text { Weight }\end{array}$ & $\mathbf{M H}^{+}$ & $\mathbf{M}^{+}$ & $\begin{array}{c}(\mathbf{M}+\mathbf{H})^{+} / \mathbf{M}^{+} \\
\text {ratio }^{b}\end{array}$ & $(\mathrm{M}-\mathrm{H})^{+}$ & Other ions \\
\hline $2 a$ & 213 & $214(60)$ & $213(100)$ & 0.60 & $212(40)$ & $\begin{array}{l}169(9) \\
147(21) \\
132(30)\end{array}$ \\
\hline $2 b$ & 215 & $216(100)$ & $215(63)$ & 1.59 & --- & $\begin{array}{l}147(54) \\
132(36)\end{array}$ \\
\hline $2 c$ & 272 & $273(68)$ & $272(100)$ & 0.68 & $271(10)$ & $180(54)$ \\
\hline 2d & 263 & $264(100)$ & $263(32)$ & 3.12 & --- & $\begin{array}{l}195(68) \\
193(24) \\
167(20)\end{array}$ \\
\hline $2 e$ & 261 & $262(58)$ & $261(100)$ & 0.58 & $260(34)$ & $\begin{array}{l}195(19) \\
193(14) \\
180(26)\end{array}$ \\
\hline $2 f$ & 250 & $251(100)$ & $250(95)$ & 1.05 & --- & $\begin{array}{l}184(60) \\
169(75)\end{array}$ \\
\hline
\end{tabular}

${ }^{a}$ For each spectrum, the most abundant ion was given an abundance 100; the matrix ions were omitted; the mass of each ion was calculated with the most abundant isotope of each element, ${ }^{b}$ Ratio of abundances.

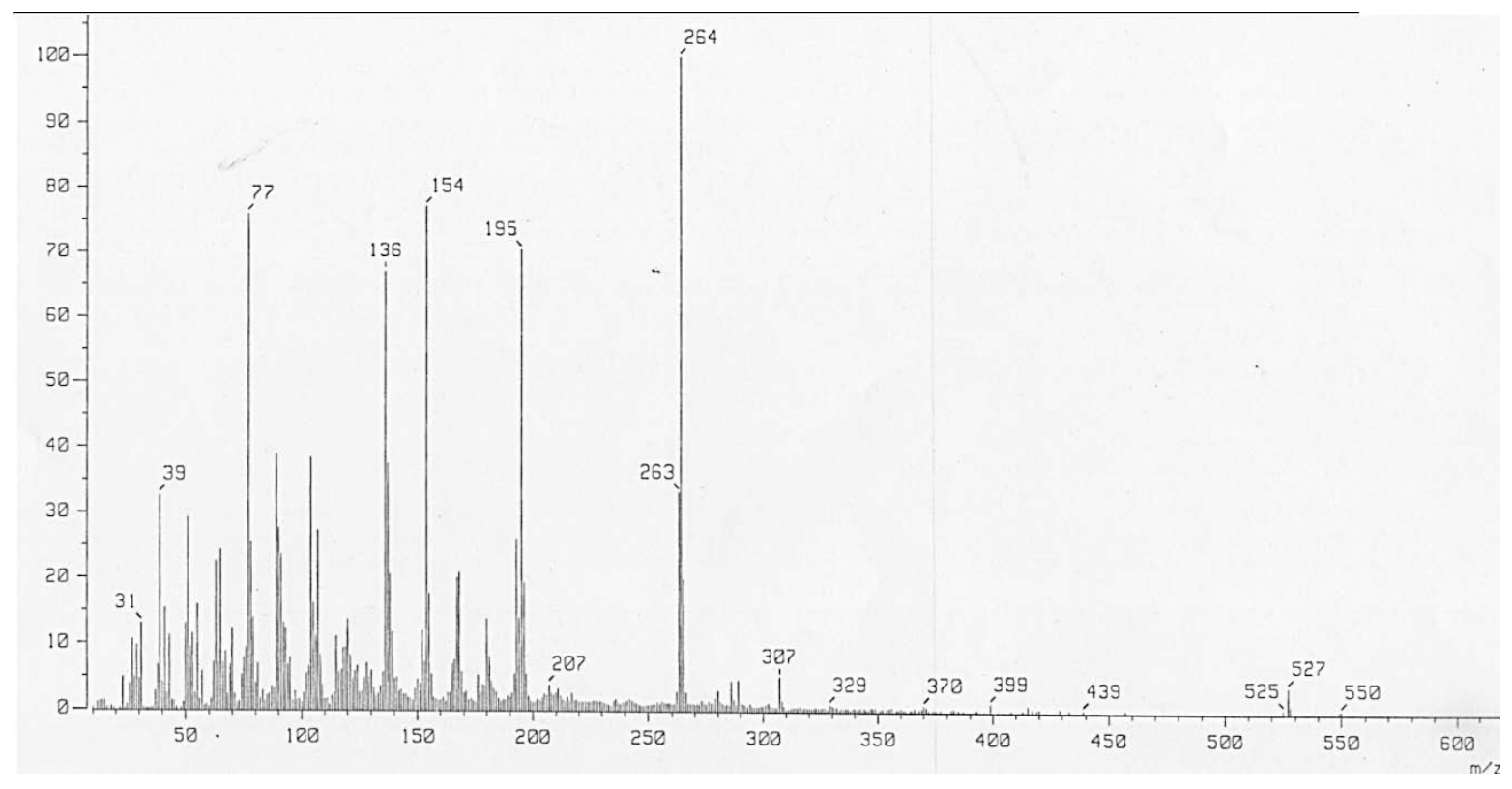

Figure 3. Positive ion FAB mass spectrum of compound 2d recorded with NBA 


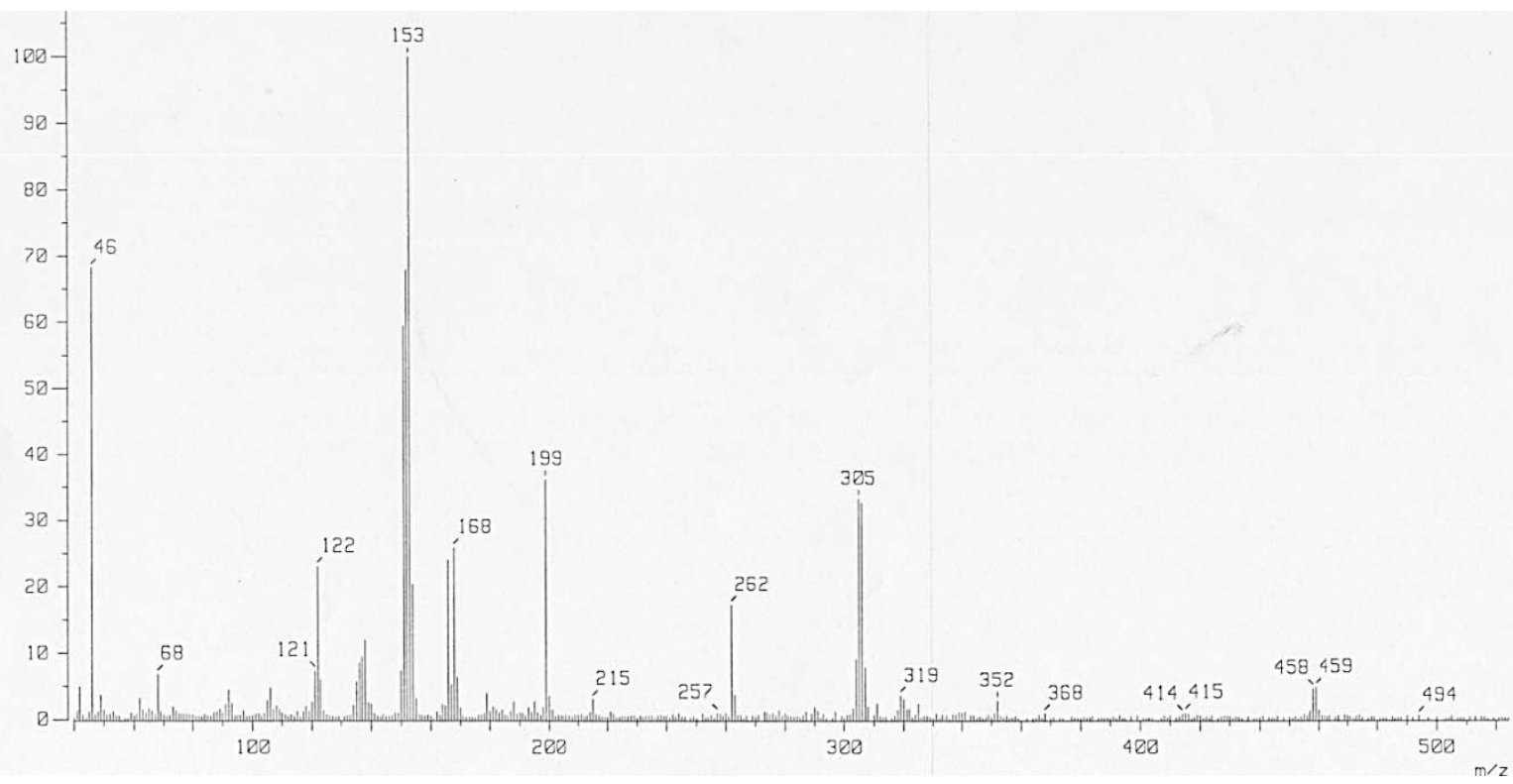

Figure 4. Negative ion FAB mass spectrum of compound 2d recorded with NBA

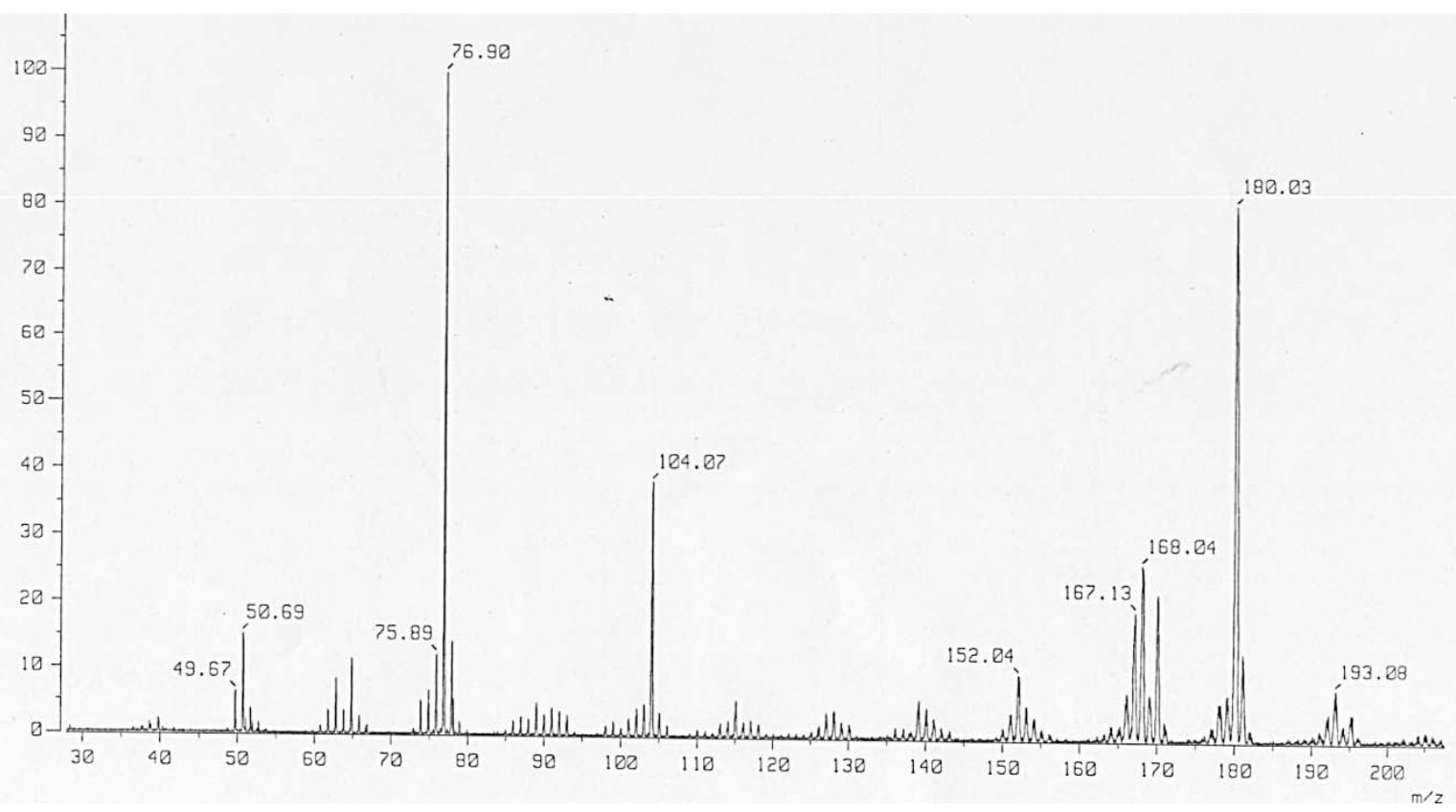

Figure 5. CAD mass spectrum of the molecular ion of compound 2c

The effect of the basicity of the triazolyl residue on the stabilisation of the $(\mathrm{M}+\mathrm{H})^{+}$ion and the effect of the IMHB on the destabilisation of the $\mathrm{M}^{+}$ion can be represented by the following equation: $(\mathrm{M}+\mathrm{H})^{+} / \mathrm{M}^{+}$ratio $=(1.9 \pm 0.3)$ Tri $+(0.9 \pm 0.2) \mathrm{IMHB}, \mathrm{n}=6, \mathrm{R}^{2}=0.95$ where Tri $=1$ if a triazole is present and 0 if it is absent and IMHB $=1$ or 0 if an IMHB is present or absent (Scheme 3). 
<smiles>[R3]N=CC1=CC=CC1=CN([R])[R]</smiles>

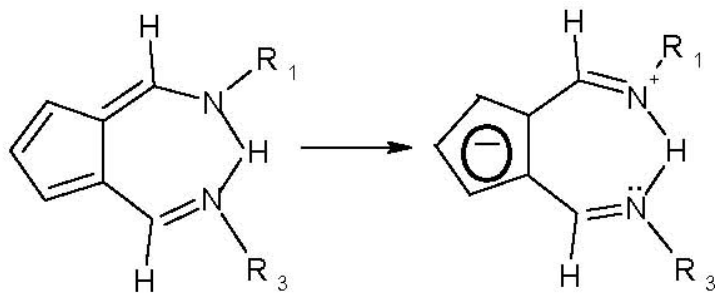

\section{Scheme 3}

In the negative ion spectra, ions related to the NBA matrix ${ }^{16}(\mathrm{~m} / \mathrm{z} 46,122,153,199,305,306$, $352,458,459)$ are numerous and abundant and a single ion featuring the compound under study i.e. $(\mathrm{M}-\mathrm{H})^{-}$is detected with a low abundance (Figures 2 and 4 for the negative ion spectra of compounds 2c and $\mathbf{2 d}$, respectively).

Although fragment ions were detected in all positive FAB mass spectra of compounds 2 , tandem experiments were undertaken to provide unambiguous structural assessments. ${ }^{17}$ Indeed, matrix ions were interfering with these low mass ions in the FAB spectra whereas collision activated dissociation (CAD) spectra contained solely the fragment ions issued from the selected precursor ion. For instance, a fragment ion at $\mathrm{m} / \mathrm{z} 180$ was seen in the positive ion FAB spectrum of compound 2c. The CAD spectrum of the molecular ion $\mathrm{M}^{+}$at $m / z 272$ is reproduced in Figure 5 and displayed the aforementioned fragment ion at $\mathrm{m} / \mathrm{z} 180$ but also additional ions at $\mathrm{m} / \mathrm{z} 168$, 104 and 77. The latter at $\mathrm{m} / \mathrm{z} 77$ could have been mistaken with a NBA related ion in the direct FAB experiment.

All CAD data are compiled in Table 3. The most abundant ion was chosen as precursor ion i.e. $\mathrm{M}^{+}$for structure $\mathbf{2 a}, \mathbf{2 c}, \mathbf{2} \mathbf{e}$ and $\mathrm{MH}^{+}$for $\mathbf{2 b}, \mathbf{2} \mathbf{d}$ and $\mathbf{2 f}$. All CAD spectra contained the ion at $\mathrm{m} / \mathrm{z} 77$, which can be attributed to the even electron ion $\mathrm{C}_{6} \mathrm{H}_{5}{ }^{+}$, particularly stable in mass spectrometry, thus featuring the cycle. Two observed fragmentations allowed to identify the $\mathrm{R}_{3}$ substituent (Table 3). First, $\mathrm{R}_{3}$ and $\mathrm{R}_{3} \mathrm{H}$ were lost from $\mathrm{M}^{+}$and $\mathrm{MH}^{+}$, respectively. Second, $\mathrm{RNH}_{3}$ and $\mathrm{R}_{3} \mathrm{NH}_{2}$ were lost from $\mathrm{M}^{+}$and $\mathrm{MH}^{+}$, respectively. 
Table 3. CAD Spectra. Comp. Studied Ion $m / z$ Fragment ions Neutral loss

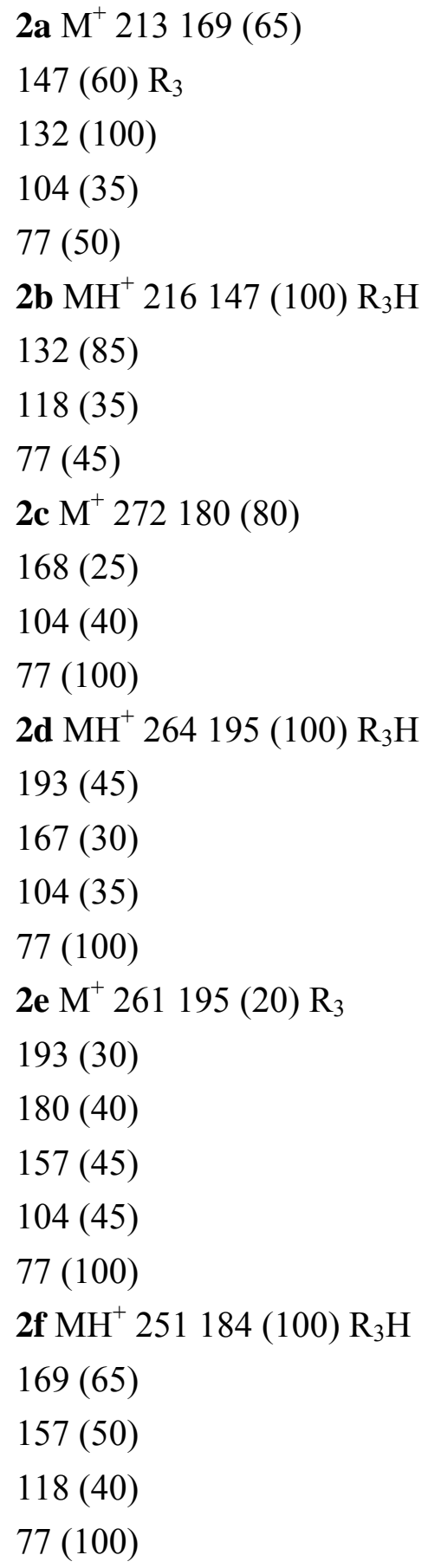




\section{Conclusions}

FAB mass spectrometry is a standard analytical technique to characterise organic molecules. The assumption that an abundant protonated molecular ion is produced in the positive mode is not necessarily valid and must be considered with caution according to the nature of the studied compound. Indeed, in some cases, protonation may impart some destabilisation and thus is disfavoured. Under such conditions, the choice of the matrix is the key step to achieve a successful analysis. In contrast to glycerol, ionization by electron transfer is allowed with the oxidative NBA matrix producing informative ions i.e. molecular ion as well as fragment ions. Such particular behaviour previously demonstrated with pyrazolo[1,2-a]pyrazoles was extended to fulvenes, a second family of nitrogen containing molecules. Finally, compounds of type 4 cannot be considered as non-classical aromatic compounds, although the strong IMHB has important consequences on their behaviour in mass spectrometry.

\section{Acknowledgement}

Thanks are given to the Ministery of Education and Culture of Spain (DGES, Project number PB96-001-C03) for economic support.

\section{References}

1. Barber, M., Bordoli, R. S., Sedgwick, R. D., Tyler, A. N. Nature 1981, 293, 270.

2. Jagerovic, N., Elguero, J., Aubagnac, J.-L. Tetrahedron 1996, 53, 6733.

3. Enjalbal, C.; Aubagnac, J.-L., Trofimenko, S., Claramunt, R. M., Sanz, D., Elguero, J. J.Heterocycl. Chem. 1998, 34, 1405.

4. Perez Torralba, M. Ph. D. Thesis, in preparation.

5. Hafner, K.; Kramer, H. A. E.; Musso, H.; Ploss, G.; Schulz, G. Chem. Ber. 1964, 97, 2066.

6. (a) Gilli, G., Bellucci, F., Ferretti, V., Bertolasi, V. J. Am. Chem. Soc. 1989, 111, 1023. (b) Bertolasi, V. Gilli, P., Ferretti, V., Gilli, G. Acta Crystallogr. Sect. B 1995, 51, 1004. (c) Bertolasi, V. Gilli, P., Ferretti, V., Gilli, G. J. Chem. Soc. Perkin Trans. 2 1997, 945.

7. Müller-Westerhoff, U. J. Am. Chem. Soc. 1970, 92, 4849.

8. Ammon, H. L., Müller-Westerhoff, U. Tetrahedron 1974, 30, 1437.

9. (a) Day, R. J., Unger, S. E., Cooks, R. G. Anal. Chem. 1980, 52, 557A. (b) Pachuta, S. J.; Cooks, R. G. Chem. Rev. 1987, 87, 647. 
10. Nedderman, A. N. R., Williams, D. H. Biolog. Mass Spectrom. 1991, 20, 289.

11. Aubagnac, J.-L., Gilles, I., Lazaro, R., Claramunt, R. M., Gosselin, G., Martinez, J. Rapid Commun. Mass Spectrom. 1995, 9, 509.

12. Takayama, M., Tanaka, T., Nomura, T. Org. Mass Spectrom. 1993, 28, 1529.

13. Takayama, M. Rapid Commun. Mass Spectrom. 1994, 8, 309.

14. Takayama, M. J. Am. Soc. Mass Spectrom. 1995, 6, 114.

15. Catalán, J.; Abboud, J. L. M., Elguero, J. Adv. Heterocycl. Chem. 1987, 41, 187.

16. Aubagnac, J.-L. Rapid Commun. Mass Spectrom. 1990, 4, 114.

17. McLafferty, F. W. Tandem Mass Spectrometry Wiley: New York, 1983. 